\title{
CD44 promotes the migration of bone marrow-derived mesenchymal stem cells toward glioma
}

\author{
QIANG YIN ${ }^{1}$, YANG-YANG ZHOU ${ }^{2}$, PENG WANG $^{1}$, LI MA $^{1}$, PENG LI ${ }^{1}$, \\ XIAO-GUANG WANG ${ }^{1}$, CHUN-HUA SHE $^{1}$ and WEN-LIANG LI ${ }^{1}$ \\ ${ }^{1}$ Department of Neurosurgery and Neuro-Oncology, Tianjin Medical University Cancer Institute and Hospital, \\ National Clinical Research Center for Cancer, Tianjin Key Laboratory of Cancer Prevention and Therapy, \\ Tianjin 300060; ${ }^{2}$ Division of Pulmonary Medicine, Tianjin Institute of Respiratory Diseases, \\ Tianjin Haihe Hospital, Tianjin 300222, P.R. China
}

Received December 10, 2014; Accepted January 13, 2016

DOI: $10.3892 / \mathrm{ol} .2016 .4270$

\begin{abstract}
Previous in vivo and in vitro studies have shown that human mesenchymal stem cells (MSCs) exhibit tropism for gliomas. However, the mechanism underlying this directed migration remains unclear. The aim of the present study was to investigate the possible mechanism underlying platelet-derived growth factor-BB (PDGF-BB)-induced chemotactic migration of bone marrow-derived MSCs (BMSCs) toward glioma. Rat glioma C6 cell-conditioned medium was utilized to evaluate the chemotactic response of BMSCs toward glioma using an in vitro migration assay. Recombinant rat PDGF-BB was added to $\mathrm{C} 6$ cell-conditioned medium to assess its effect on the tropism of BMSCs. The effect of PDGF-BB on the expression levels of cluster of differentiation (CD)44 in BMSCs was evaluated by reverse transcription-polymerase chain reaction (RT-PCR) and immunofluorescence assays. The results revealed that chemotactic migration was induced in BMSCs by rat glioma C6 cell-conditioned medium, which was enhanced by PDGF-BB treatment in a dose-dependent manner. Furthermore, RT-PCR and immunofluorescence assays showed that CD44 expression was upregulated in BMSCs following treatment with $40 \mathrm{ng} / \mathrm{ml}$ PDGF-BB for $12 \mathrm{~h}$. Additionally, 3-h pretreatment with the anti-CD44 neutralizing antibody OX-50 was observed to attenuate the tropism of BMSCs toward glioma in the presence or absence of PDGF-BB. The results of the present study indicate that CD44 mediates the tropism of BMSCs toward glioma, and PDGF-BB promotes the migration of BMSCs toward glioma via the upregulation of CD44 expression in BMSCs. These
\end{abstract}

Correspondence to: $\mathrm{Dr}$ Wen-Liang Li, Department of Neurosurgery and Neuro-Oncology, Tianjin Medical University Cancer Institute and Hospital, National Clinical Research Center for Cancer, Tianjin Key Laboratory of Cancer Prevention and Therapy, 1 Huanhuxi Road, Hexi, Tianjin 300060, P.R. China

E-mail: tjzlyinqiang@163.com

Key words: platelet-derived growth factor-BB, mesenchymal stem cell, glioma, CD44, chemostatic migration findings suggest CD44 inhibition may be a potential therapeutic target for the treatment of glioma.

\section{Introduction}

Glioma is the most common aggressive adult primary tumor of the central nervous system (1). The mortality rate associated with glioma occupies the top position among the malignant tumors worldwide (2). During the early stages (I and II) of disease, when the tumor is small, patients with glioma are usually asymptomatic, whereas grade III and IV gliomas, including glioblastoma, are aggressive and lethal malignant neoplasms (3). Glioma, in particular glioblastoma multiforme, is the most common malignant brain tumor in adults (4). The median age at diagnosis of glioblastoma patients is 65 years (5). Current treatment options include surgical resection, radiotherapy and chemotherapy (6). However, glioma carries a particularly poor prognosis, with survival measured in months rather than years (7).

The treatment approaches for malignant glioma, which is the most common type of highly aggressive primary brain tumor, are often unsuccessful due to diffuse infiltration and poor prognosis (8). A key problem regarding glioma treatment is the lack of effective tumor site-specific delivery systems available for therapeutic agents (9). Bone marrow-derived mesenchymal stem cells (BMSCs) have been shown to exhibit tropism for gliomas (10). Furthermore, these cells may be obtained easily, and may be genetically engineered and autologously transplanted, thus providing a feasible delivery vehicle for glioma-targeted therapy (11-17). Previous in vivo studies have demonstrated the efficacy of this delivery system $(12,18)$. A number of cytokines, including platelet-derived growth factor-BB (PDGF-BB), have been shown to affect the migration of BMSCs (12,19-22); however, the mechanism underlying this remains to be elucidated.

It has been established that site-directed migration involves interaction between multiple adhesion molecules on migrating cells and their corresponding ligands $(23,24)$. The cell adhesion molecule cluster of differentiation (CD)44, which is a BMSCs-specific transmembrane glycoprotein, is known to be involved in intracellular interactions that affect the motility of BMSCs (25-27). T cells migrating to inflammatory sites 
express higher levels of CD44 on their cell surface, and thus are capable of establishing more CD44-hyaluronan (HA) interactions $(28,29)$. Therefore, CD44 may exert certain effects on the chemotactic migration of BMSCs to glioma cells. In the current study, we evaluated the role of CD44 in the tropism of BMSCs for glioma cells.

\section{Materials and methods}

Cell culture. Rat glioma C6 cells were obtained from the Key Laboratory of Cancer Prevention and Therapy (Tianjin, China) and cultured in serum-free low glucose-Dulbecco's modified Eagle's medium (L-DMEM; Invitrogen; Thermo Fisher Scientific, Inc., Waltham, MA, USA) at $37^{\circ} \mathrm{C}$ in a humidified atmosphere of $5 \% \mathrm{CO}_{2}$. Cell culture plates, including 6-well plates, 24-well plates and $60-\mathrm{mm}$ dishes were purchased from Nest Biotechnology Co., Ltd. (Wuxi, China).

Ethical statement. All animal experiments were approved by the Animal Care and Use Committee of Tianjin Medical University Cancer Institute and Hospital (Tianjin, China), and were performed in accordance with the National Institute of Health Guide for the Care and Use of Laboratory Animals (30). A total of 20 Wistar rats were purchased from Vital River Laboratories (Beijing, China). They were housed under the specific conditions and sacrificed immediately by cervical dislocation as described previously by Yang et al (31).

BMSCs isolation. The rats were housed in the animal center of Tianjin Medical University Cancer Institute and Hospital at a temperature of $20-25^{\circ} \mathrm{C}$ and relative humidity of $50-70 \%$ on a 12-h dark/light cycle and provided a standard pelleted diet and water ad libitum. Male rats of 4 weeks old were used, and they were individually sacrificed by cervical dislocation. Four-week-old male Wistar rats were used for BMSCs isolation based on the principle of their adherence to plastic (32). Briefly, bone marrow cells collected from the bilateral tibias and femurs of sacrificed rats were cultured in L-DMEM supplemented with 10\% fetal bovine serum (Invitrogen; Thermo Fisher Scientific, Inc.). Three days later, adherent cells were passaged to fresh medium to discard non-adherent cells, and were subsequently grown to full confluence. Next, 6,000 cells $/ \mathrm{cm}^{2}$ cells were subcultured and grown to full confluence again prior to subculturing. Cells at fourth passage were identified as BMSCs, and used for the following experiments, as previously described (33).

Immunocytochemistry. BMSCs were collected and seeded onto $1.5 \%$ gelatin-coated coverslips. At $80 \%$ confluence, the C6 cells seeded on sterilized glass slides were allowed to attach overnight. Following fixation with $4 \%$ paraformaldehyde (Sigma-Aldrich, St. Louis, MO, USA) for $1 \mathrm{~h}$ at $4^{\circ} \mathrm{C}$, cells were washed with phosphate-buffered saline (PBS; Sigma-Aldrich) three times for 20 min each, prior to incubation with PBS for $60 \mathrm{~min}$ at $4^{\circ} \mathrm{C}$. Fixed cells were incubated with rabbit polyclonal anti-human anti-PDGF-BB antibody (dilution, 1:100; catalog no., ab23914; Abcam, Cambridge, MA, USA) at $4^{\circ} \mathrm{C}$ overnight, followed by incubation with goat anti-rabbit immunoglobulin $\mathrm{G}$, horseradish peroxidase-conjugated secondary antibody (dilution, 1:1,000; catalog no. 7074; Cell Signaling Technology, Danvers, MA, USA) for $45 \mathrm{~min}$ at room temperature. Next, the membranes were stained with 3,3'-diaminobenzidine (Sigma-Aldrich) and hematoxylin (Sigma-Aldrich), and slides were mounted with 50\% glycerol (Sinopharm Chemical Reagent Co., Ltd., Shanghai, China) prior to capturing images with a microscope (Eclipse ME600; Nikon Corp., Tokyo, Japan).

Immunofluorescence. BMSCs incubated in PDGF-BB-supplemented C6-conditioned medium for $12 \mathrm{~h}$ were fixed in $3.7 \%$ paraformaldehyde and permeabilized in pre-chilled acetone (Sinopharm Chemical Reagent Co., Ltd.). BMSCs incubated with serum-free L-DMEM were used as a negative control. Upon blocking with $5 \%$ bovine serum albumin (Sigma-Aldrich) in PBS for $1 \mathrm{~h}$, the cells were incubated with polyclonal rabbit anti-human/mouse/rat CD44 antibody (dilution, 1:100; catalog no., PA1021-2; Wuhan Boster Biological Technology, Ltd., Wuhan, China) for $4 \mathrm{~h}$ at room temperature, followed by incubation with rhodamine-conjugated goat anti-mouse immunoglobulin G secondary antibody (dilution, 1:100; catalog no., ZF-0313; Zhongshan Golden Bridge Biotechnology Co., Ltd, Beijing, China) for $1 \mathrm{~h}$ at room temperature. Images were captured using a laser confocal microscope (TCS SP5; Leica Microsystems, Inc., Buffalo Grove, IL, USA).

Reverse transcription-polymerase chain reaction (RT-PCR). RT-PCR was performed to examine the transcriptional levels of PDGF-BB in C6 cells and CD44 in PDGF-BB-treated BMSCs using a 2400 GeneAmp ${ }^{\circledR}$ PCR system (Applied Biosystems; Thermo Fisher Scientific, Inc.). BMSCs incubated with serum-freeL-DMEM served as a negative control. Total RNA was extracted from cells using TRIzol reagent (Invitrogen; Thermo Fisher Scientific, Inc.), and cDNA was obtained from $1 \mu \mathrm{g}$ RNA using the ImProm-II ${ }^{\mathrm{TM}}$ Reverse Transcription System (Promega Corporation, Madison, WI, USA) according to the manufacturer's instructions. The primers used for PCR, synthesized by Sangon Biotech Co., Ltd. (Shanghai, China), were as follows: Sense, 5'-CTTTAAGAAGGCCACGGTGA-3' and anti-sense, 5'-TCCAAGGGTCTCCTTCAGTG-3' for PDGF-BB; sense, 5'-AAGACATCGATGCCTCAAAC-3' and anti-sense, 5'-CTC CAGTAGGCTGTGAAGTG-3' for CD44 (34); and sense, 5'-TAT CCAGGCTGTGCTATCCC-3' and anti-sense, 5'-CCATCTCTT GCTCGAAGTCC-3' for $\beta$-actin. PCR was performed under the following conditions for PDGF-BB: Denaturation at $94^{\circ} \mathrm{C}$ for $46 \mathrm{~min}$, followed by 40 cycles of $94^{\circ} \mathrm{C}$ for $15 \mathrm{sec}, 62^{\circ} \mathrm{C}$ for $1 \mathrm{~min}$ and $72^{\circ} \mathrm{C}$ for $1 \mathrm{~min}$, with a final extension step at $72^{\circ} \mathrm{C}$ for $7 \mathrm{~min}$; PCR was performed under the following conditions for CD44: Denaturation for $95^{\circ} \mathrm{C}$ for $15 \mathrm{~min}$, followed by 45 cycles of $94^{\circ} \mathrm{C}$ for $15 \mathrm{sec}, 55^{\circ} \mathrm{C}$ for $30 \mathrm{sec}$ and $72^{\circ} \mathrm{C}$ for $30 \mathrm{sec}$. The PCR products were separated using gel electrophoresis on a $2 \%$ agarose gel (Sigma-Aldrich). The bands were scanned using ChemiImager 5500 version 2.03 software (Alpha Innotech, San Leandro, CA, USA). Integrated density values were calculated using a computerized image analysis system (Fluor Chen 2.0; Bio-Rad, Hercules, CA, USA) and normalized to $\beta$-actin. Agarose gel, which was prepared in $1 \times$ TAE buffer containing $40 \mathrm{mM}$ Tris-acetic acid ( $\mathrm{pH}$ 8.5; Tris-base was purchased from Sigma Aldrich; acetic acid was from Sinopharm Chemical Reagent Co., Ltd.) and $2 \mathrm{mM}$ ethylenediaminetetraacetic acid (Sinopharm Chemical Reagent Co., Ltd.), was supplemented with $0.5 \mu \mathrm{g} / \mathrm{mL}$ ethidium bromide (Sigma-Aldrich). Wide Mini-Sub Cell GT Horizontal Electrophoresis System and PowerPac ${ }^{\mathrm{TM}}$ 
A

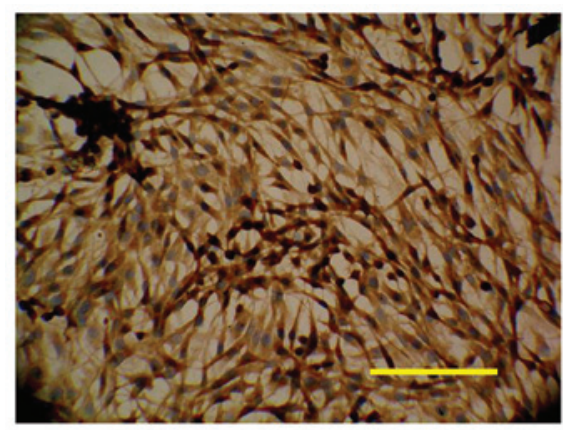

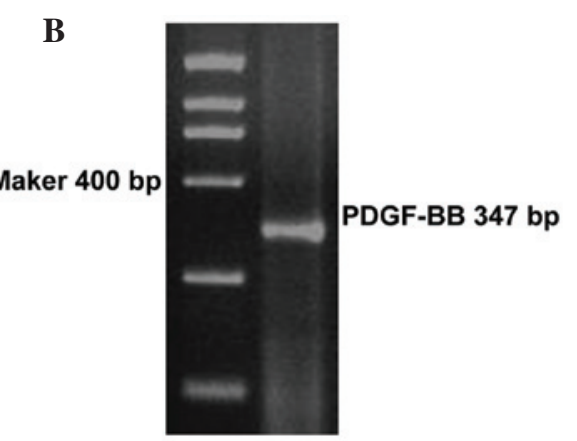

Figure 1. PDGF-BB expression in C6 glioma cells. (A) Representative image of PDGF-BB immunocytochemistry in C6 cells (magnification, x200; scale bar, $200 \mu \mathrm{m}$ ). (B) Reverse transcription-polymerase chain reaction of PDGF-BB expression in C6 glioma cells. PDGF-BB, platelet-derived growth factor-BB.

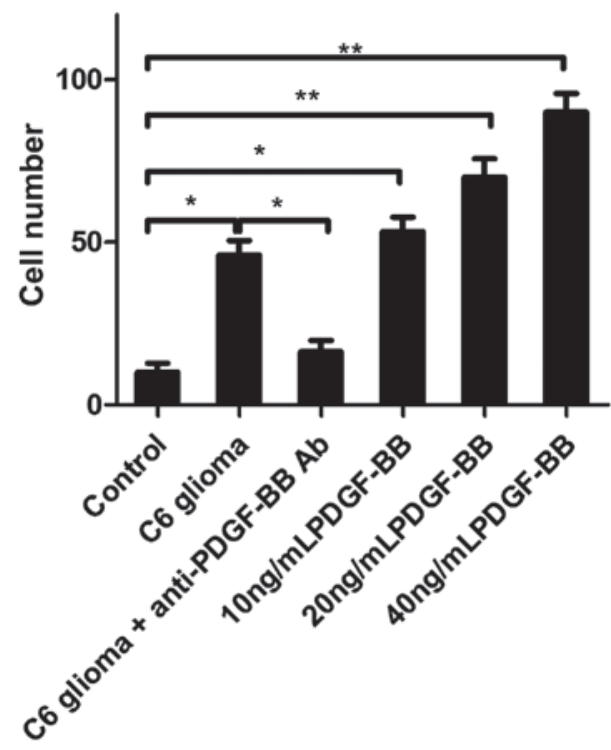

Figure 2. PDGF-BB promotes the tropism of BMSCs toward C6 glioma. In vitro migration assay showing the chemostatic migration of BMSCs toward C6 cell-conditioned medium supplemented with anti-PDGF-BB antibody or with 10,20 or $40 \mathrm{ng} / \mathrm{ml}$ PDGF-BB. The results are expressed as the mean \pm standard deviation of three independent experiments. ${ }^{*} \mathrm{P}<0.05$, ${ }^{* * *} \mathrm{P}<0.01$ vs. control. PDGF-BB, platelet-derived growth factor-BB; BMSCs, bone marrow-derived mesenchymal stem cells; $\mathrm{Ab}$, antibody.

Universal Power Supply (Bio-Rad Laboratories, Inc., Hercules, CA, USA) were applied for gel electrophoresis, with voltage and time set at $100 \mathrm{~V}$ and $20 \mathrm{~min}$, respectively. DNA fragments were visualized and quantified using ChemiDoc MP system (Bio-Rad Laboratories, Inc.), and relative amounts of CD44 transcripts were determined against $\beta$-actin expression.

In vitro migration assay. The culture medium for rat glioma C6 cells was collected following 24-h incubation. Upon centrifugation at $1,000 \mathrm{x}$ g for $15 \mathrm{~min}$ at room temperature, and subsequent sterilization by $0.22-\mathrm{mm}$ filtration (Thermo Fisher Scientific, Inc.), the supernatant was identified as C6 cell-conditioned medium. For the migration assay, BMSCs at a density of $2 \times 10^{5}$ cells $/ \mathrm{ml}$ were seeded in the upper chamber of a Transwell plate containing an 8- $\mu \mathrm{m}$ pore membrane (Costar; Corning Incorporated, Corning, NY, USA), and C6 cell-conditioned medium in the presence or absence of recombinant rat PDGF-BB (catalogue no. 220-BB-010; R\&D Systems, Inc., Minneapolis, MN, USA) and serum-free L-DMEM containing
10, 20 or $40 \mu \mathrm{g} / 1$ PDGF-BB was added to the lower well of the Transwell plates. Serum-free L-DMEM served as a negative control. Cells were incubated for $24 \mathrm{~h}$ prior to formalin fixation and hematoxylin staining. Images of nine randomly selected fields were captured, and cells were counted.

To block CD44 activity, C6-conditioned medium in the presence or absence of PDGF-BB ( $40 \mathrm{ng} / \mathrm{ml})$ was incubated with mouse monoclonal anti-rat CD44 neutralizing antibody (dilution, 1:1,000; catalog no., OX-50; Abcam) for $3 \mathrm{~h}$ at room temperature, prior to being added to the lower chamber of the Transwell plates. Serum-free L-DMEM served as a negative control. The subsequent procedures were performed as described above. Briefly, BMSCs were seeded in the upper chamber, followed by an incubation of $24 \mathrm{~h}$ at $37^{\circ} \mathrm{C}$. Migrated cells were stained prior to counting. An inverted microscope (Zeiss Axio Vert A1 Inverted, Carl Zeiss Canada Ltd., North York, ON, Canada) equipped with a charge-coupled device camera (Orca ER; Hamamatsu Photonics K.K., Hamamatsu, Japan) was used to visualize and image stained cells, at x400 magnification.

Statistical analysis. All data were analyzed using SPSS 13.0 statistical software (SPSS Inc., Chicago, IL, USA). Two-tailed unpaired Student's t-test was used to determine the significance of differences between groups. $\mathrm{P}<0.05$ was considered to indicate a statistically significant difference. All experiments were performed at least twice, and results were expressed as the mean \pm standard deviation.

\section{Results}

Rat glioma C6 cells express PDGF-BB. The expression levels of PDGF-BB in rat glioma $\mathrm{C} 6$ cells were analyzed. As shown in Fig. 1A, PDGF-BB protein was highly expressed in the cytoplasm of $\mathrm{C} 6$ cells (Fig. 1A). In addition, a clear cDNA band corresponding to PDGF-BB was identified in C6 cells using RT-PCR (Fig. 1B).

C6 cells induce chemotactic migration of BMSCs via expression and secretion of PDGF-BB. To evaluate the effect of PDGF-BB on tropism of BMSCs toward glioma, an in vitro migration assay was performed. As shown in Fig. 2, increased levels of migration of BMSCs were observed in the C6 cell-conditioned medium-treated group after $24 \mathrm{~h}$ treatment compared with the normal medium-treated group, which was attenuated by 4 -h pretreatment with 
A

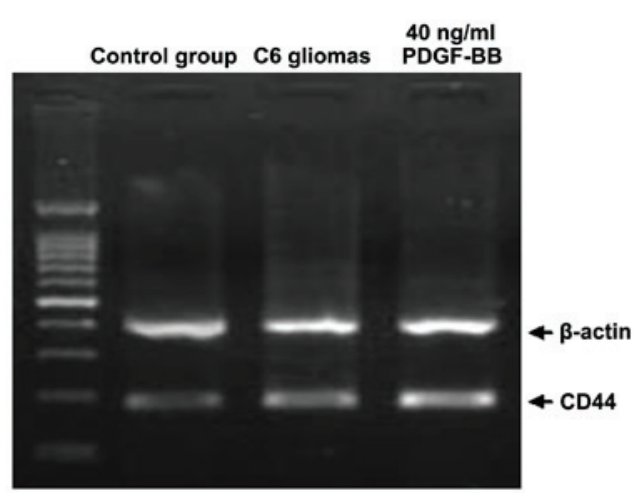

C

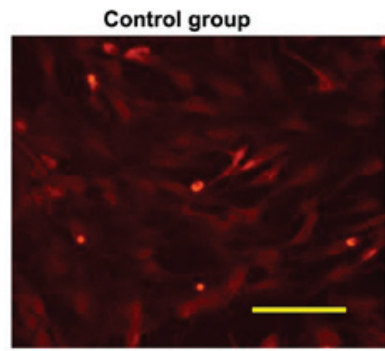

B
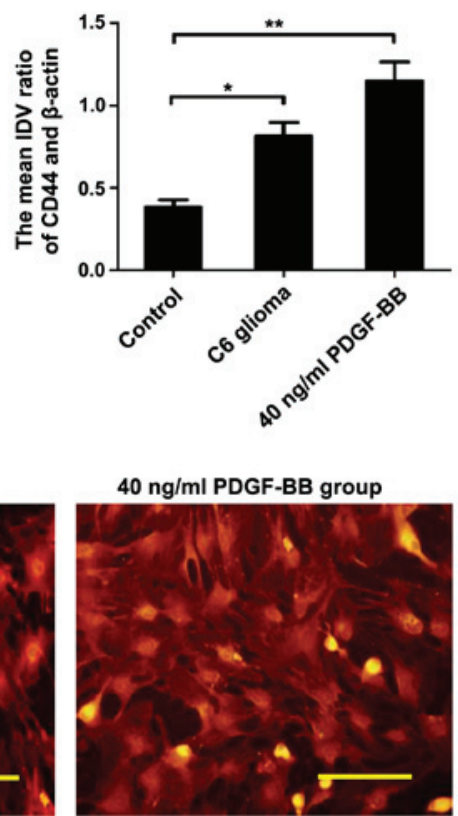

Figure 3. PDGF-BB upregulates CD44 expression in BMSCs. (A) Reverse transcription-polymerase chain reaction was performed to evaluate the changes in CD44 mRNA expression levels under PDGF-BB conditions of $40 \mathrm{ng} / \mathrm{ml}$ or C6 glioma. (B) Results demonstrated that $40 \mathrm{ng} / \mathrm{ml}$ PDGF-BB and C6 glioma significantly elevated the CD44 expression of BMSCs compared with control groups ("P<0.01; $\left.{ }^{* *} \mathrm{P}<0.001\right)$. (C) Immunofluorescence revealing the effect of treatment with $40 \mathrm{ng} / \mathrm{ml}$ PDGF-BB on the protein levels of CD44 in BMSCs. Yellow staining indicates CD44 expression (magnification, $\mathrm{x} 400$; scale bar, $100 \mu \mathrm{m}$ ). PDGF-BB, platelet-derived growth factor-BB; CD, cluster of differentiation; BMSCs, bone marrow-derived mesenchymal stem cells; IDV, integrated density value.

A

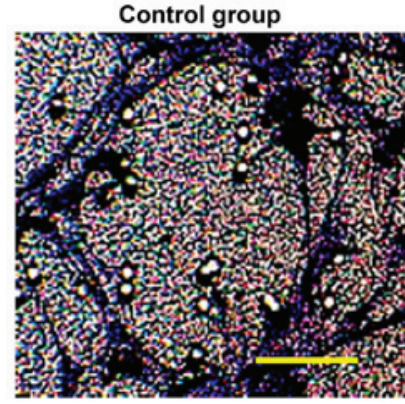

40 ng/mI PDGF-BB

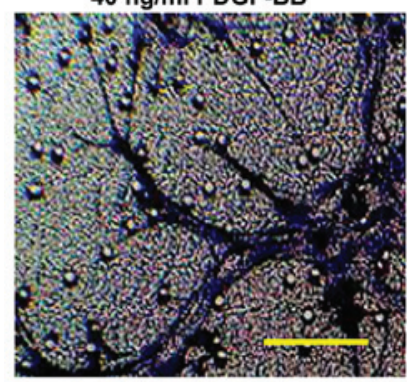

C6 gliomas

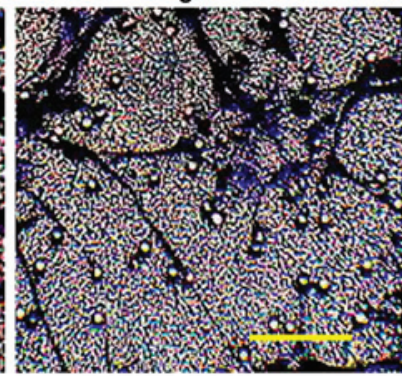

40 ng/ml PDGF-BB+OX-50



C6 gliomas+0X-50

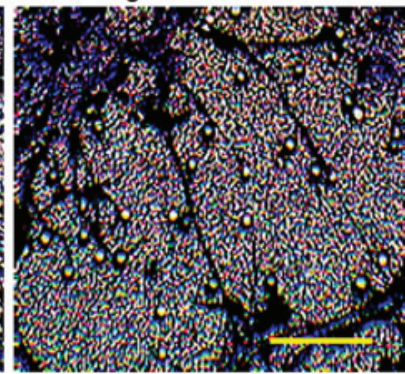

B

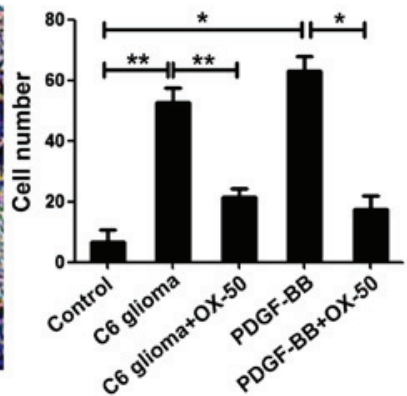

Figure 4. Anti-CD44 antibody attenuates C6 cell-induced and PDGF-BB-promoted chemostatic migration of BMSCs. (A) The effect of CD44 in chemostatic migration of BMSCs was evaluated using OX-50, an anti-CD44 antibody. Representative images of each group are presented (magnification, x400; scale bar, $100 \mu \mathrm{m}$ ). (B) Quantification of the data corresponding to panel A. The graph represents the mean \pm standard deviation of three independent experiments. ${ }^{*} \mathrm{P}<0.05$ and ${ }^{* *} \mathrm{P}<0.01$ vs. control. CD, cluster of differentiation; PDGF-BB, platelet-derived growth factor-BB; BMSCs, bone marrow-derived mesenchymal stem cells.

anti-PDGF-BB antibody, indicating that $\mathrm{C} 6$ cell-induced chemostatic migration of BMSCs may occur as a result of PDGF-BB secretion in the C6 cell-conditioned medium. Additionally, supplementing C6 cell-conditioned medium with recombinant rat PDGF-BB enhanced C6 cells-induced chemostatic migration of BMSCs in a dose-dependent manner (Fig. 2), thus demonstrating that PDGF-BB promotes the tropism of BMSCs. 
PDGF-BB upregulates the expression of the standard form of $C D 44$. CD44, as a marker for BMSCs, has been reported to be involved in the mobilization and chemostatic migration of BMSCs (35). To evaluate the effect of PDGF-BB on CD44 expression in BMSCs, RT-PCR and immunofluorescence assays were performed. As shown in Fig. 3, the transcriptional and protein levels of CD44 in BMSCs were increased in the C6 cell-conditioned medium-treated group, and PDGF-BB augmented this effect, indicating that PDGF-BB promotes the chemostatic migration of BMSCs toward glioma via the upregulation of CD44 expression in BMSCs.

CD44 mediates the tropism of BMSCs for glioma. OX-50, an anti-CD44 neutralizing antibody, was used to assess the role of CD44 in the tropism of BMSCs. As shown in Fig. 4, pretreatment of C6 cell-conditioned medium with the anti-CD44 antibody OX-50 for $3 \mathrm{~h}$ blocked the C6 cell-induced and the PDGF-BB-promoted chemostatic migration of BMSCs, suggesting that CD44 may act as a molecular bridge between BMSCs and glioma.

\section{Discussion}

PDGF is a strong mitogen and chemoattractant for fibroblasts, myofibroblasts and smooth muscle cells $(36,37)$. PDGF-BB, a member of the PDGF family, has been demonstrated to induce chemotactic migration of cells of mesenchymal origin (38). A number of glioma cells express and secrete PDGF, with high-grade gliomas expressing higher levels of PDGF compared with low-grade gliomas (34). In the present study, rat glioma C6 cells expressed high levels of PDGF-BB, and PDGF-BB augmented the chemostatic migration of BMSCs induced by C6 cell-conditioned medium, indicating that PDGF-BB may mediate glioma-induced tropism of BMSCs. However, further studies are required to corroborate these findings.

CD44, as a unique surface antigen of BMSCs $(25,26,33,39)$, is involved in various cellular processes, including proliferation, differentiation, survival and migration (40). The main function of CD44 is to regulate the motility and chemotaxis of BMSCs (41). Previous studies have demonstrated that CD44 is localized on the leading edge of migrating cells $(42,43)$, and its inhibition attenuates macrophage chemotaxis (44) and fusion (45). Additionally, loss of CD44 decreases the migratory ability of human colon cancer cells, while overexpression of CD44 promotes their migration (46), indicating the importance of CD44 in such processes. The major isoform of CD44 present in MSCs is the standard form, termed CD44s. In the present study, PDGF-BB was observed to increase the transcriptional and protein levels of CD44 in BMSCs. In addition, C6 cell-induced and PDGF-BB-promoted chemostatic migration of BMSCs was markedly attenuated by the anti-CD44 neutralizing antibody OX-50, suggesting that C6 cells may induce BMSCs tropism via the expression and secretion of PDGF-BB, which upregulates CD44 expression in BMSCs. The CD44-HA interaction presents a critical step required for cell migration (35), and has been reported to be involved in the migration of $\mathrm{CD} 34^{+}$stem cells to the bone marrow, as well as in the adhesion, motility and invasion of breast cancer cells $(47,48)$. However, these mechanisms require further investigation.
In conclusion, the results of the current study revealed that CD44 mediates the tropism of BMSCs to glioma, and PDGF-BB promotes the migration of BMSCs toward glioma via upregulation of CD44 expression in BMSCs. These findings suggest CD44 inhibition may be a potential therapeutic target for the treatment of glioma.

\section{Acknowledgements}

The present study was supported by the Doctoral Initial Funding of the National Clinical Research Center for Cancer, Tianjin Medical University Cancer Institute and Hospital (Tianjin, China; grant. no. B1318) and the Young Program of Natural Science Funding of Tianjin (grant no., 15JCQNJC44800).

\section{References}

1. Barbarin A, Seite P, Godet J, Bensalma S, Muller JM and Chadeneau C: Atypical nuclear localization of VIP receptors in glioma cell lines and patients. Biochem Biophys Res Commun. 454:524-530.2014.

2. Malone HR and Bruce JN: Editorial: laser interstitial thermal therapy: an effective treatment for focally recurrent high grade glioma. Neurosurg Focus. 37:E2.2014.

3. Wolking $\mathrm{S}$, Lerche $\mathrm{H}$ and Dihne $\mathrm{M}$ : Episodic itch in a case of spinal glioma. BMC Neurol. 13:124.2013.

4. Ostrom QT, Gittleman H, Farah P, Ondracek A, Chen Y, Wolinsky Y, Stroup NE, Kruchko C and Barnholtz-Sloan JS: CBTRUS statistical report: Primary brain and central nervous system tumors diagnosed in the United States in 2006-2010. Neuro Oncol 15 (Suppl 2): ii1-ii56, 2013.

5. Chakrabarti I, Cockburn M, Cozen W, Wang YP and Preston-Martin S: A population-based description of glioblastoma multiforme in Los Angeles County, 1974-1999. Cancer 104: 2798-2806, 2005.

6. Woehrer A, Bauchet L and Barnholtz-Sloan JS: Glioblastoma survival: Has it improved? Evidence from population-based studies. Curr Opin Neurol 27: 666-674, 2014.

7. Yabroff KR, Harlan L, Zeruto C, Abrams J and Mann B: Patterns of care and survival for patients with glioblastoma multiforme diagnosed during 2006. Neuro Oncol 14: 351-359, 2012.

8. Stupp R, Mason WP, van den Bent MJ, Weller M, Fisher B, Taphoorn MJ, Belanger K, Brandes AA, Marosi C, Bogdahn U, et al; European Organisation for Research and Treatment of Cancer Brain Tumor and Radiotherapy Groups; National Cancer Institute of Canada Clinical Trials Group: Radiotherapy plus concomitant and adjuvant temozolomide for glioblastoma. N Engl J Med 352: 987-996, 2005.

9. Ho IA, Toh HC, Ng WH, Teo YL, Guo CM, Hui KM and Lam PY: Human bone marrow-derived mesenchymal stem cells suppress human glioma growth through inhibition of angiogenesis. Stem Cells 31: 146-155, 2013.

10. Hu Y, Cheng P, Xue YX and Liu YH: Glioma cells promote the expression of vascular cell adhesion molecule-1 on bone marrow-derived mesenchymal stem cells: A possible mechanism for their tropism toward gliomas. J Mol Neurosci 48: 127-135, 2012.

11. Nakamura K, Ito Y, Kawano Y, Kurozumi K, Kobune M, Tsuda H, Bizen A, Honmou O, Niitsu Y and Hamada H: Antitumor effect of genetically engineered mesenchymal stem cells in a rat glioma model. Gene Ther 11: 1155-1164, 2004.

12. Nakamizo A, Marini F, Amano T, Khan A, Studeny M, Gumin J, Chen J, Hentschel S, Vecil G, Dembinski J, et al: Human bone marrow-derived mesenchymal stem cells in the treatment of gliomas. Cancer Res 65: 3307-3318, 2005.

13. Bang OY, Lee JS, Lee PH and Lee G: Autologous mesenchymal stem cell transplantation in stroke patients. Ann Neurol 57: 874-882, 2005.

14. Karussis D,Kassis I,KurkalliBGandSlavinS:Immunomodulation and neuroprotection with mesenchymal bone marrow stem cells (MSCs): A proposed treatment for multiple sclerosis and other neuroimmunological/neurodegenerative diseases. J Neurol Sci 265: 131-135, 2008 . 
15. Liu H, Honmou O, Harada K, Nakamura K, Houkin K, Hamada H and Kocsis JD: Neuroprotection by PIGF gene-modified human mesenchymal stem cells after cerebral ischaemia. Brain 129: 2734-2745, 2006.

16. Caplan AI and Bruder SP: Mesenchymal stem cells: Building blocks for molecular medicine in the 21st century. Trends Mol Med 7: 259-264, 2001.

17. Colter DC, Class R, DiGirolamo CM and Prockop DJ: Rapid expansion of recycling stem cells in cultures of plastic-adherent cells from human bone marrow. Proc Natl Acad Sci USA 97: 3213-3218, 2000.

18. Wu X, Hu J, Zhou L, Mao Y, Yang B, Gao L, Xie R, Xu F, Zhang D, Liu J and Zhu J: In vivo tracking of superparamagnetic iron oxide nanoparticle-labeled mesenchymal stem cell tropism to malignant gliomas using magnetic resonance imaging. Laboratory investigation. J Neurosurg 108: 320-329, 2008 .

19. Schichor C, Birnbaum T, Etminan N, Schnell O, Grau S, Miebach S, Aboody K, Padovan C, Straube A, Tonn JC and Goldbrunner R: Vascular endothelial growth factor A contributes to glioma-induced migration of human marrow stromal cells (hMSC). Exp Neurol 199: 301-310, 2006.

20. Cheng P, Gao ZQ, Liu YH and Xue YX: Platelet-derived growth factor $\mathrm{BB}$ promotes the migration of bone marrow-derived mesenchymal stem cells towards C6 glioma and up-regulates the expression of intracellular adhesion molecule-1. Neurosci Lett 451: 52-56, 2009.

21. Hata N, Shinojima N, Gumin J, Yong R, Marini F, Andreeff M and Lang FF: Platelet-derived growth factor BB mediates the tropism of human mesenchymal stem cells for malignant gliomas. Neurosurgery 66: 144-157, 2010.

22. Ozaki Y, Nishimura M, Sekiya K, Suehiro F, Kanawa M, Nikawa H, Hamada T and Kato Y: Comprehensive analysis of chemotactic factors for bone marrow mesenchymal stem cells. Stem Cells Dev 16: 119-129, 2007.

23. Vicente-Manzanares M and Horwitz AR: Cell migration: An overview. Methods Mol Biol 769: 1-24, 2011.

24. Misra S, Heldin P, Hascall VC, Karamanos NK, Skandalis SS, Markwald RR and Ghatak S. Hyaluronan-CD44 interactions as potential targets for cancer therapy. FEBS J 278: 1429-1443, 2011

25. Lisignoli G, Cristino S, Piacentini A, Cavallo C, Caplan AI and Facchini A: Hyaluronan-based polymer scaffold modulates the expression of inflammatory and degradative factors in mesenchymal stem cells: Involvement of Cd44 and Cd54. J Cell Physiol 207: 364-373, 2006.

26. Schweizer PA, Krause U, Becker R, Seckinger A, Bauer A, Hardt C, Eckstein V, Ho AD, Koenen M, Katus HA and Zehelein J: Atrial-radiofrequency catheter ablation mediated targeting of mesenchymal stromal cells. Stem Cells 25: 1546-1551, 2007.

27. Mylona E, Jones KA, Mills ST and Pavlath GK: CD44 regulates myoblast migration and differentiation. J Cell Physiol 209: 314-321, 2006.

28. DeGrendele HC, Kosfiszer M, Estess P and Siegelman MH: CD44 activation and associated primary adhesion is inducible via T cell receptor stimulation. J Immunol 159: 2549-2553, 1997.

29. Mohamadzadeh M, DeGrendele H, Arizpe H, Estess P and Siegelman M: Proinflammatory stimuli regulate endothelial hyaluronan expression and CD44/HA-dependent primary adhesion. J Clin Invest 101: 97-108, 1998.

30. National Research Council of the National Academies: Guide for the care and use of laboratory animals. 8th edition. National Academies Press, Washington DC, USA, p11, 2011.
31. Yang C, Zhou L, Gao X, Chen B, Tu J, Sun H, Liu X, He J, Liu J and Yuan Q: Neuroprotective effects of bone marrow stem cells overexpressing glial cell line-derived neurotrophic factor on rats with intracerebral hemorrhage and neurons exposed to hypoxia/reoxygenation. Neurosurgery 68: 691-704, 2011.

32. Geng J, Peng F, Xiong F, Shang Y, Zhao C, Li W and Zhang C: Inhibition of myostatin promotes myogenic differentiation of rat bone marrow-derived mesenchymal stromal cells. Cytotherapy 11: 849-863, 2009

33. Conget PA and Minguell JJ: Phenotypical and functional properties of human bone marrow mesenchymal progenitor cells. J Cell Physiol 181: 67-73, 1999.

34. Hermanson M, Funa K, Hartman M, Claesson-Welsh L, Heldin CH, Westermark B and Nistér M: Platelet-derived growth factor and its receptors in human glioma tissue: Expression of messenger RNA and protein suggests the presence of autocrine and paracrine loops. Cancer Res 52: 3213-3219, 1992.

35. Zhu H, Mitsuhashi N, Klein A, Barsky LW, Weinberg K, Barr ML, Demetriou A and Wu GD: The role of the hyaluronan receptor CD44 in mesenchymal stem cell migration in the extracellular matrix. Stem Cells 24: 928-935, 2006.

36. Soma Y, Takehara K and Ishibashi Y. Alteration of the chemotactic response of human skin fibroblasts to PDGF by growth factors. Exp Cell Res 212: 274-277, 1994.

37. Trojanowska M. Role of PDGF in fibrotic diseases and systemic sclerosis. Rheumatology (Oxford) 47 (Suppl 5): v2-v4, 2008.

38. Rönnstrand L and Heldin CH: Mechanisms of platelet-derived growth factor-induced chemotaxis. Int J Cancer 91: 757-762, 2001.

39. Stamenkovic I, Aruffo A, Amiot M and Seed B: The hematopoietic and epithelial forms of CD44 are distinct polypeptides with different adhesion potentials for hyaluronate-bearing cells. EMBO J 10: 343-348, 1991.

40. Naor D, Nedvetzki S, Golan I, Melnik L and Faitelson Y: CD44 in cancer. Crit Rev Clin Lab Sci 39: 527-579, 2002.

41. Fanning A, Volkov Y, Freeley M, Kelleher D and Long A: CD44 cross-linking induces protein kinase C-regulated migration of human T lymphocytes. Int Immunol 17: 449-458, 2005.

42. Legg JW, Lewis CA, Parsons M, Ng T and Isacke CM: A novel PKC-regulated mechanism controls CD44 ezrin association and directional cell motility. Nat Cell Biol 4: 399-407, 2002.

43. Thorne RF, Legg JW and Isacke CM: The role of the CD44 transmembrane and cytoplasmic domains in co-ordinating adhesive and signalling events. J Cell Sci 117: 373-380, 2004

44. Zhu B, Suzuki K, Goldberg HA, Rittling SR, Denhardt DT, McCulloch CA and Sodek J: Osteopontin modulates CD44-dependent chemotaxis of peritoneal macrophages through G-protein-coupled receptors: Evidence of a role for an intracellular form of osteopontin. J Cell Physiol 198: 155-167, 2004.

45. Sterling H, Saginario C and Vignery A: CD44 occupancy prevents macrophage multinucleation. J Cell Biol 143: 837-847, 1998.

46. Subramaniam V, Vincent IR, Gardner H, Chan E, Dhamko H and Jothy S: CD44 regulates cell migration in human colon cancer cells via Lyn kinase and AKT phosphorylation. Exp Mol Pathol 83: 207-215, 2007.

47. Avigdor A, Goichberg P, Shivtiel S, Dar A, Peled A, Samira S, Kollet O, Hershkoviz R, Alon R, Hardan I, et al: CD44 and hyaluronic acid cooperate with SDF-1 in the trafficking of human $\mathrm{CD} 34^{+}$stem/progenitor cells to bone marrow. Blood 103: 2981-2989, 2004

48. Afify A, Purnell P and Nguyen L: Role of CD44s and CD44v6 on human breast cancer cell adhesion, migration and invasion. Exp Mol Pathol 86: 95-100, 2009. 